\title{
UNA ENCINA (Quercus sp.) EN MONEDAS Y BILLETES DE COSTA RICA (1848-1948)
}

\section{AN OAK TREE (Quercus Sp.) IN COINS AND PAPER MONEY OF COSTA RICA (1848-1948)}

\author{
José A. Vargas Zamora \\ jose.vargas@ucr.ac.cr
}

Fecha de recepción: 17 de mayo 2013 - Fecha de aceptación: 22 de octubre 2013

\begin{abstract}
Resumen
En 1848 el Dr. Castro Madriz decretó la fundación de la República de Costa Rica y sus nuevas monedas. En las de plata se grabó un árbol de encina (Quercus sp.) como símbolo de la fortaleza y hospitalidad de la nueva República. Estas monedas fueron acuñadas entre 1850 y 1862 (1/4, 1/8 y 1/16 de Peso) y entre 1864 y 1875 (50, 25, 10, y 5 centavos de Peso). Este trabajo aporta información sobre el significado de la encina en el contexto socio-político de Costa Rica a mediados del siglo XIX. También se dan estimaciones de las cantidades acuñadas de cada valor, para un total aproximado de 1.871.000 monedas. Los cuartos de Peso de 1853 y 1855 son escasos, mientras que las de 50 centavos de 1975 son relativamente comunes y todas las denominaciones con poco desgaste son raras. El árbol de Q. salicifolia es similar al grabado en las monedas. Después de 1880 una rama de encina fue grabada en diferentes emisiones de papel moneda, especialmente como corona para la cabeza de la libertad. El último billete con este símbolo fue emitido en 1943, con valor de 1 colón.
\end{abstract}

Palabras clave: encina, roble, Quercus, 1/4 de Peso 1850, 50 centavos 1875, monedas, Costa Rica.

\begin{abstract}
In 1848 Dr. Castro Madriz issued the decree which established the Republic of Costa Rica and its new coinage. An oak tree (Quercus sp.) was engraved on silver coins as a symbol of the strength and hospitality of the new Republic. These coins were minted between 1850 and 1862 (1/4, 1/8 and 1/16 of Peso) and between 1864 and 1875 (50, 25, 10, and 5 cents of Peso). This paper provides information on the significance of the oak tree in the socio-political context of mid XIX century Costa Rica. It also provides estimates of the number of pieces minted of each value for a total of approximately 1.871 .000 coins. The quarter Pesos of 1853 and 1855 are scarce while the 50 cents of 1875 are relatively common, and all denominations with little wear are rare. The Q. salicifolia tree is similar to that engraved on the coins. After 1880 an oak branch was engraved in different issues of paper money, mainly as a crown for the head of Liberty. The last bill with this symbol was issued in 1943, with a value of 1 colon.
\end{abstract}

Key words: oak tree, oak wreath, Quercus, $1 / 4$ Peso 1850, 50 cents 1875, coins, Costa Rica.

1 Escuela de Biología, Sede Rodrigo Facio. Universidad de Costa Rica. 


\section{Introducción}

Desde tiempos antiguos muchas especies de hierbas, arbustos y árboles han sido asociadas a virtudes, poderes mágicos y medicinales, o a deidades. Aquellas especies de árboles con maderas duras, o que viven por centurias son símbolos preferidos para indicar fortaleza y robustez. Según Morales (2010), los árboles incluidos en la familia Fagaceae, representados por el género Quercus con más de 600 especies, son conocidos popularmente como robles o encinas. Estos árboles solitarios o formando bosques (robledales o encinares) habitan desde climas templados hasta los trópicos. La expresión "tan fuerte como un roble" sobrevive para referirse a personas que alcanzan edad avanzada y en buen estado de salud.

Según Ciesla (2002) la excelente calidad de la madera de roble ha favorecido su uso desde tiempos antiguos para la construcción de edificios, embarcaciones, muebles y toneles para añejar licores. Además, de la corteza del alcornoque (Quercus suber) se fabrican tapones de corcho para botellas de vino. Otras especies de encinas son fuentes de taninos y de colorantes. Muchas de las semillas (bellotas) son comestibles y algunas, tostadas y molidas, sirven como sustituto del café. En un texto de medicina de principios del siglo XIX, se lee:

(...) Encina (Quercus robur L. Quercus cortex officin.). Es un árbol que crece en las selvas de Europa. No tiene olor, su sabor es estíptico. Se usa en los flujos y hemorragias pasivas en forma de cocimiento, el cual se hace con una onza de corteza, y una libra de agua o vino: la dosis es de una a tres onzas cada tres horas (Blasco Jorro, 1815).

La encina es también símbolo de hospitalidad, pues en Génesis 18: 1-4, se la menciona así:

(...) Aparecióse Yavé a Abraham junto al encinar de Mambré, estando él sentado ante su tienda durante el calor del día. Alzados los ojos miró y he aquí que vio tres hombres que estaban de pie cerca de él. Apenas los vio, corrió a su encuentro desde la puerta de la tienda y postrándose en tierra dijo: "Mi Señor, te lo ruego, si he hallado gracia a tus ojos, no pases sin detenerte con tu siervo. Se os traerá un poco de agua, os lavaréis los pies y reposaréis a la sombra de éste árbol" (La Biblia, Ediciones Paulinas, Madrid, 1978).
De acuerdo con Bean (1919) el árbol bíblico podría haber pertenecido a la especie Quercus coccifera.

En Costa Rica desde tiempos coloniales el real de plata $(8$ reales $=1$ Peso de plata, 2 pesos $=1$ escudo de oro) era la moneda de referencia. Después de la Independencia en 1821 y a partir de 1825 se acuñaron varios tipos de monedas de plata y de oro en las que se grabaron especies botánicas, cada una asociada a uno o varios símbolos concretos. En 1848 el Dr. José María Castro Madriz, primer Presidente de la República de Costa Rica, emitió el 29 de setiembre el decreto que define el Pabellón y el Escudo de Armas de la nueva República, así como el diseño de las nuevas monedas de oro y de plata. Sobre esta última se indicó (el subrayado es nuestro):

(...) la de plata contendrá un árbol de encina sobre un terreno figurado; y la orla del reverso de todas las monedas, sean de oro o plata tendrá éste título "América Central" junto con el nombre del ensayador, en iniciales, el valor correspondiente de la pieza y su respectiva ley (Chacón-Hidalgo, 2000).

El objetivo de este escrito es aportar algunas reflexiones sobre la escogencia de un árbol de encina como símbolo de la nueva República de Costa Rica, así como sobre las cantidades y calidades de las monedas acuñadas con ese símbolo entre 1850 y 1875 , y del uso de ramas de encina en billetes en el siglo XX.

\section{Encina, roble, o ambos}

No existe una separación científica clara entre los términos roble y encina, pues ambos se refieren a especies del género Quercus. Según Cendrero Curiel (1932) la especie más conocida de roble en Europa es Quercus robur, mientras que el término encina se asocia en España a $Q$.ilex.

Por su parte en Costa Rica existe una decena de especies de robles o encinos, algunas con árboles que sobrepasan los 40 metros de altura (Morales, 2010). Sobre el particular, el viajero irlandés Thomas F. Meagher, quien estuvo de visita en Costa Rica en 1858, anotó sobre su excursión al Volcán Irazú y sobre los terrenos de la hacienda de Potrero Cerrado: 
(...) Aunque se llama hacienda de ganado, la mayor parte está cultivada y produce en abundancia las mejores patatas, duraznos y membrillos. Del viento penetrante que a menudo sopla del cono del volcán la protege la ancha faja de robles alpinos, que llaman encinas...(Fernández-Guardia, 2002).

Según Céspedes Porras (1991) entre los usos de las encinas en Costa Rica, árboles de Quercus seemannii, conocido en el país como roble-encino y que crece por encima de los $1.000 \mathrm{~m}$, eran cortados para fabricar carbón. No obstante, algunas especies de encinas también se encuentran en tierras bajas de Costa Rica, como Quercus oleoides, que es común en Guanacaste y pierde sus hojas en la estación seca (Boucher, 1981). Además, arriba de los $1.800 \mathrm{~m}$, los extensos bosques de Quercus copeyensis en la Cordillera de Talamanca tenían fama mundial por la altura de sus árboles (cerca de $50 \mathrm{~m}$ ) y su abundancia, hasta que la construcción de la carretera Interamericana los hizo accesibles y según las palabras proféticas de don Anastasio Alfaro y otros botánicos:

(...) De no tomarse medidas inmediatas, su destrucción será segura. A lo largo de la carretera debiera conservarse una faja por lo menos, como un bosque o parque nacional costarricense y conservarse para deleite de millares de turistas que de seguro atraerá, una vez terminada la guerra..., Los madereros están ahora volteando estos robles milenarios, en la mera orilla de la carretera y transportándolos en camiones a los centros consumidores. Los carboneros contribuyen también a su destrucción. La riqueza de tanino de la corteza despertará también la codicia de otros industriales...(Alfaro et al., 1944).

\section{La encina en monedas del mundo}

Según Carson (1962) la acuñación de monedas metálicas se inició alrededor del año 650 A.C., en la región de Lidia, en Asia Menor. Esas primeras monedas eran de una mezcla de oro y plata conocida como electrum y algunas tenían grabadas figuras de animales como el león, símbolo del reino de Lidia. Así, las figuras servían para identificar la procedencia de las monedas y alguna característica importante de la ciudad, región, o país emisor. Por ejemplo, un buho se asociaba a la ciudad de Atenas, una espiga de cebada (Hordeum vulgare) a la ciudad de Metapontum en Italia, un cangrejo a la región de Agrigentum en la costa de Sicilia y un laberinto a la ciudad de Cnossos en la isla de Creta (Klawans, 1959). Por lo tanto, desde la invención de las monedas las figuras grabadas en ellas transmitían mensajes concretos reconocibles por los usuarios, fueran estos la mayoría analfabetos o hablasen otro idioma. Por ejemplo, la región de Macedonia bajo dominación romana emitió (158-149 A.C.) tetradracmas de plata con la efigie de la diosa Artemisa (Diana) en una de las caras de la moneda y en la otra cara el garrote utilizado por Hércules en sus trabajos (Figura 1A). El garrote aparece rodeado por dos ramas de encina, que era el árbol dedicado a Zeus (Júpiter), el padre de los dioses. La encina simbolizaba poder y fortaleza.

Es importante mencionar que las tetradracmas pesaban cerca de 17 gramos (g). Por lo tanto, la dracma griega antigua pesaba alrededor de 4.25 g. Los romanos utilizaron el denario, cuyo peso era similar al de la dracma, pero que a partir del emperador Nerón (54-68 D.C.) tuvo un peso de $3.43 \mathrm{~g}$. El real español, cuyo peso antes de 1728 era precisamente $3.43 \mathrm{~g}$ después fue establecido en $3.38 \mathrm{~g}$. Las monedas de plata utilizadas en Costa Rica desde tiempos coloniales tenían como base el real español de $3.38 \mathrm{~g}$ de peso teórico.

De acuerdo con Yeoman (1976) el primer grabado de un árbol de encina (sin hojas) en monedas del Nuevo Mundo fue hecho entre 1660 y 1667 en la colonia inglesa de Massachussets. Se acuñó peniques y chelines (fechados 1652 por conveniencia política, excepto la de dos peniques de 1662) que circularon hasta $1682 \mathrm{El}$ árbol grabado fue probablemente Quercus rubra o roble rojo, nativo de América del Norte y llamado así por el color de su follaje otoñal.

Durante la primera mitad del siglo XX árboles de encina (con hojas) fueron grabados en dos monedas que ilustramos: La primera (Figura 1B) es la de cinco marcos alemanes (1927-1933, plata 500/1000, peso 25.0 g.), con el árbol de la especie Quercus robur. La segunda (Figura 1C) es una pieza conmemorativa del tricentenario (1935) de la colonia inglesa de Connecticut, por valor de medio dólar (plata 900/1000, peso 12.5 g.), con el árbol de la especie Quercus alba, el roble blanco. Ambas emisiones son de interés en el contexto de las monedas costarricenses, pues son respectivamente, la primera y segunda 
A

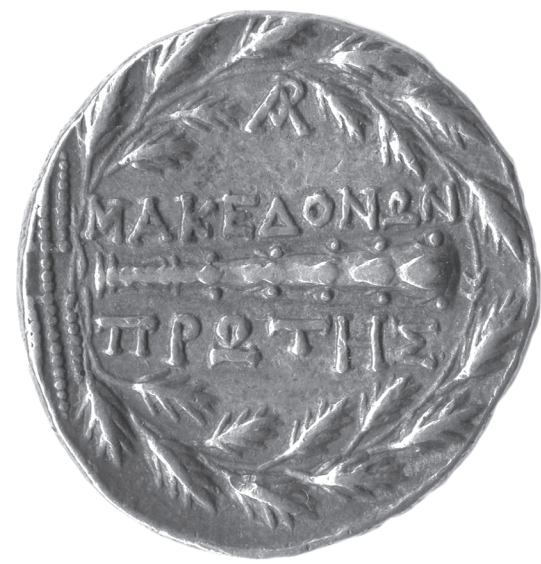

B

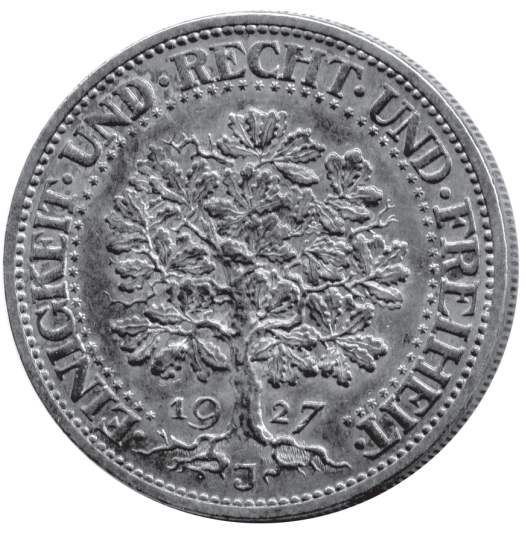

C

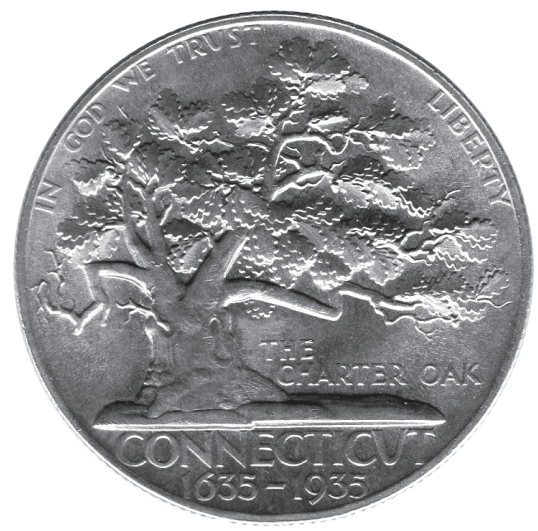

Figura 1

Tres monedas con encinas: A. Tetradracma de Macedonia bajo dominio romano (158-149 A.C.), $30 \mathrm{~mm}$. El garrote de Hércules rodeado por una corona de hojas de encina. B. Cinco marcos, 35 mm, Alemania, 1927. El árbol con hojas es Quercus robur. C. Medio dólar, $30 \mathrm{~mm}$. Estados Unidos de América. Tricentenario de la colonia de Connecticut 1635-1935. El árbol es Q. alba, o roble blanco. emitidas en el mundo con el grabado de un árbol de encina después de las de Costa Rica de 185075 (ver catálogos de Krause y Mishler, 2001, 2004).

Asimismo, en el siglo XX y principios del actual, ramas de encina con sus frutos (bellotas) han sido grabadas en monedas europeas como las de Alemania, Croacia, Dinamarca, Francia, Italia y Suiza, entre otras. Las hojas de borde ondulado y las bellotas permiten asociarlas con la especie Quercus robur. Esta especie es el árbol nacional de Alemania, Estonia, Francia, Gales, Inglaterra y Polonia.

\section{Costa Rica antes de la encina}

Después de 1821 los gobernantes costarricenses definieron nuevos símbolos para identificar al país y a la Federación Centroamericana, que Costa Rica pasó a integrar en 1824. En el caso de las monedas era necesario sustituir por otros símbolos el busto del rey y las armas de España, propios de las monedas coloniales en uso a principios del siglo XIX. Para esto se eligió grabar en el anverso de las de plata una cadena de cinco montañas (cada una representando a un estado de la Federación) y un sol naciente. En el reverso se incluyó desde 1824 en monedas producidas en Guatemala, un árbol nativo de la región, la ceiba o ceibo (Ceiba pentandra) como símbolo de libertad y al que se le augura que libre, crezca fecundo.

El primer esfuerzo para dotar al Estado de Costa Rica de moneda propia fue en 1825 con la corta operación del ingenio de metales de Los Horcones (en la vecindad de La Garita, Alajuela), que acuñó en las monedas de oro la figura de una palmera (Figura 2A), símbolo de rectitud y fortaleza. La palmera podría haber sido una especie local, o la datilera Phoenix dactylifera, símbolo de victoria desde tiempos bíblicos (Vargas Zamora y Gómez Laurito, 2004). Sin embargo, la palmera fue objetada por el gobierno federal y entonces las monedas de Costa Rica fueron acuñadas con el grabado de la ceiba, a partir de 1828 en las de oro y de 1831 en las de plata (Figura 2B). 


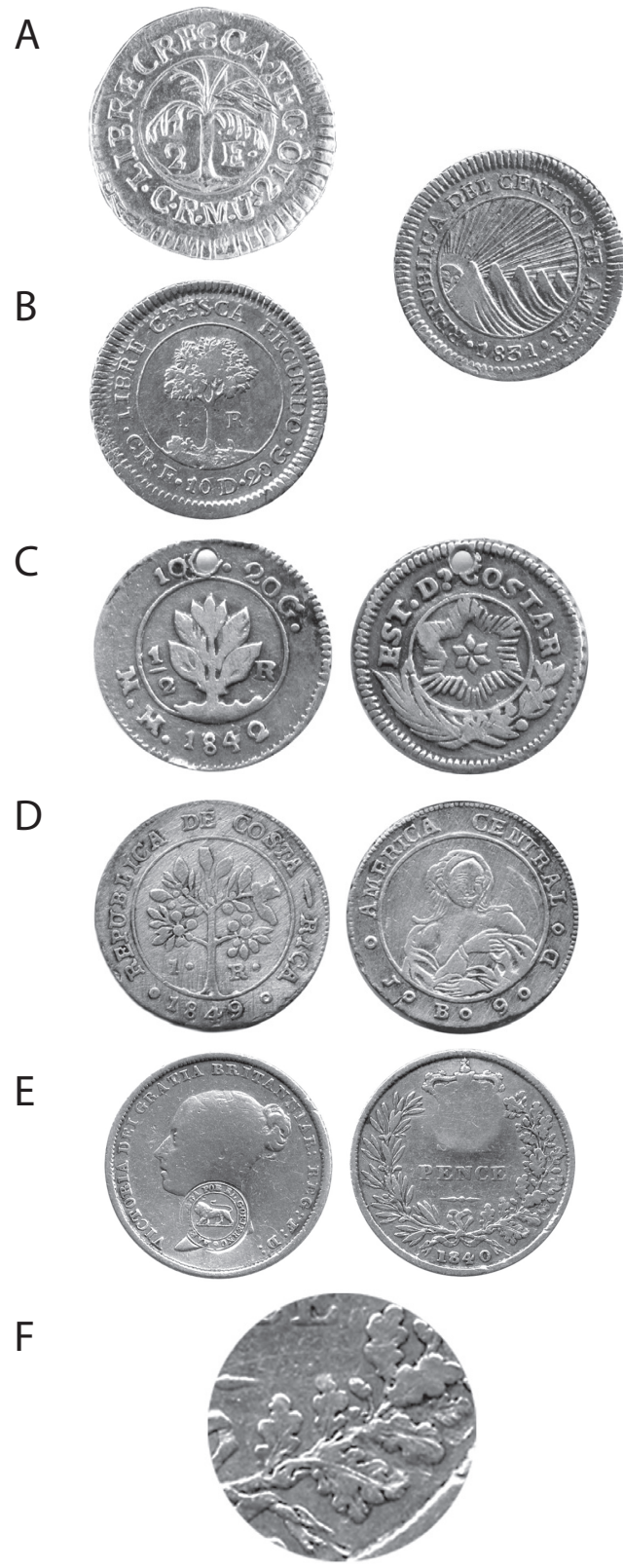

Figura 2

Monedas de Costa Rica con grabados de plantas: A. Medio escudo, 1825, $22 \mathrm{~mm}$, con una palmera similar a Phoenix dactylifera. Colección Museo BCCR. B. Anverso y reverso de un real, 1831, $23 \mathrm{~mm}$. Arbol de ceiba (Ceiba pentandra).

C. Medio real, 1842, $18 \mathrm{~mm}$. Planta de tabaco (Nicotiana tabacum). D. Un real, 1849, 20 mm. Arbusto de café (Coffea arabica). E. Six Pence (seis peniques), Inglaterra, $1840,19 \mathrm{~mm}$, contramarcado en 1850 para circular en Costa Rica por valor de un real. F. Detalle de la rama de $Q$. robur, con hojas y bellotas.
Sin embargo, don Braulio Carrillo separó en 1838 a Costa Rica de la Federación y decretó en 1840 nuevos símbolos nacionales: la bandera de dos franjas blancas con una celeste al centro (hoy símbolo de la Universidad de Costa Rica) y el Escudo de Armas formado por una estrella radiante de seis puntas, el cual fue grabado en el anverso de la moneda de oro (1 escudo) y en la de plata (1/2 real) emitidas (Vargas Zamora y Murillo Rivera, 2013). De esta manera, en el reverso de la de plata se incluyó (Figura 2C) una planta de tabaco (Nicotiana tabacum), cuyo cultivo y comercio era una de las fuentes principales de ingresos del gobierno a través del monopolio administrado por la Factoría de Tabacos, con sede en San José.

Ya en 1847 se acuñó en Costa Rica la primera moneda (1 real) conmemorativa y en la que se dibujó un arbusto de café (Coffea arabica), cuyo cultivo ya había superado al tabaco como el principal del país. El cafeto fue grabado también en el anverso de monedas de un real fechadas 1849 y 1850. Estas monedas (1847-1850) fueron conocidas como mariquitas, por la figura femenina grabada en el reverso (Figura 2D).

Para mediados del siglo XIX los cultivos del tabaco y especialmente del café habían aumentado el comercio local e internacional y la necesidad de más moneda circulante. Por tal motivo en 1845 se había resellado pesetas españolas (habilitadas para circular por el valor de 2 reales) y en 1846 se resellaron las monedas macuquinas $(1,2,4, \mathrm{y} 8$ reales) de plata legítimas, pues circulaban muchas falsas.

Debido al incremento del comercio con Inglaterra, también circulaban peniques (Six pence) y chelines (Shilling) ingleses. Los peniques y chelines fueron resellados en 1850 para circular por 1 y 2 reales, respectivamente. En los peniques aparece grabada una rama de la encina Quercus robur, con sus hojas lobuladas y bellotas características (Figura 2E, F). Por lo tanto, los costarricenses de mediados del siglo XIX ya estaban familiarizados con la encina.

En el Cuadro 1 se indican las monedas mencionadas anteriormente, la ley o contenido de plata de cada una, los valores emitidos y el peso teórico en gramos de cada una. Nótese que en 1849 (por falta de troqueles con el 
Cuadro 1

Denominación, ley, fechas de emisión y peso teórico en gramos (Según Gurdián-Montealegre, 1997) de las monedas de plata que tienen grabada una planta en el reverso y acuñadas en Costa Rica entre 1828 y 1850.

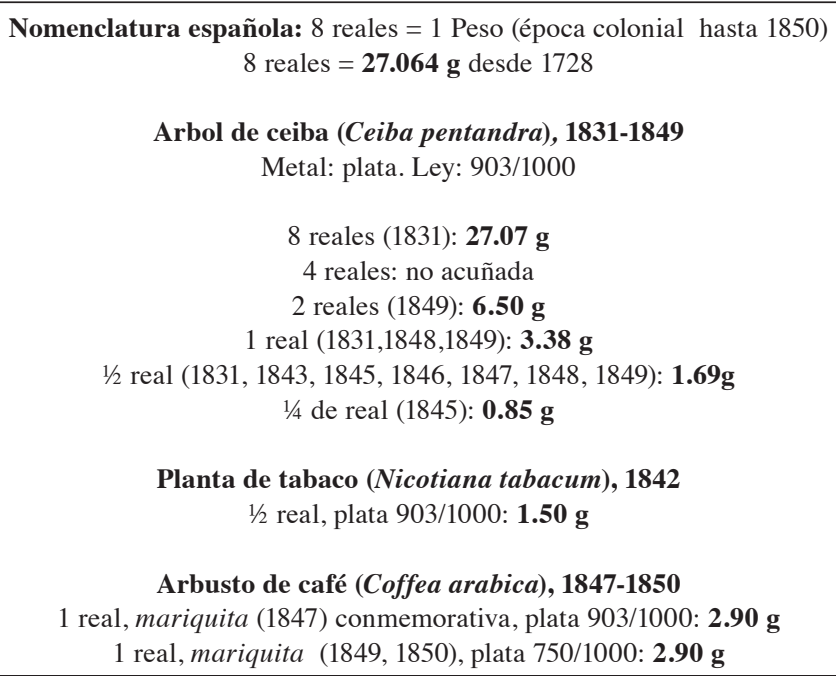

árbol de encina) se acuñaron algunas monedas con la ceiba.

\section{La República y sus nuevos símbolos}

Según lo mencioné anteriormente, con el decreto del 29 de setiembre de 1848 emitido por el Dr. Castro Madriz, Costa Rica fue constituida en República y adoptó nuevos símbolos nacionales. La primera moneda que lleva la leyenda República de Costa Rica es la de un real de 1849 (Figura 2D). Así, el decreto de 1848 especifica la adopción del árbol de encina sobre un terreno figurado en el reverso de las monedas de plata, pero sin indicar su significado. En el anverso se graba el nuevo Escudo de Armas. Con esto, los nuevos símbolos (bandera tricolor y escudo de armas), además de identificar al país ante sus ciudadanos y ante el mundo tenían dos objetivos según Chacón Hidalgo (2000):

(...) Tanto en las monedas de plata como en las de oro se rescataron dos elementos importantes, para reforzar la búsqueda del reconocimiento diplomático como República independiente por parte de las principales potencias extranjeras, y firmar tratados de comercio, amistad y navegación...
(...) los símbolos transmitidos mediante las monedas funcionaron como parte de un sistema para construir lo real y como instrumentos para la comunicación, que permitieron promover la integración de distintos grupos en torno a proyectos políticos específicos...

En el contexto del primer objetivo citado era lógico dibujar un árbol familiar para los europeos, especialmente para los alemanes, franceses, e ingleses con los que se tenían y se esperaban más lazos comerciales y culturales.

En el contexto del segundo objetivo, uno de esos proyectos políticos específicos fue el fortalecimiento de la inversión extranjera mediante el estímulo de la llegada de inmigrantes europeos. Por ejemplo, en 1850 se funda la Sociedad Berlinesa de Colonización para Centroamérica, cuyo proyecto principal fue la creación de una colonia agrícola cerca de Turrialba. Por esos años ingresan al país varios ciudadanos europeos que luego fundarían familias y empresas, así como darían impulso a los oficios, las ciencias y la medicina (ver Herrera Balharry, 1988 e Hilje Quirós, 2013). No obstante, el ambiente difícil en que se desenvolvían estos colonos está descrito en forma amena por el viajero alemán Wilhelm 
Marr, quien estuvo de visita en Costa Rica en 1853 (Marr, 2004).

Según Marr (2004) el primer colono alemán en Costa Rica había ingresado en la década anterior para laborar como ingeniero en algunas minas de oro en los montes del Aguacate y su nombre era Johann (Juan) Barth. Tal vez por sus conocimientos de metalurgia Barth sería luego nombrado ensayador y director de la Casa de Moneda y sus iniciales J. B. aparecen en las monedas entre 1847 y 1864 (Figuras 2D y 3). Por esto, es de suponer que Barth estaba familiarizado con las encinas europeas y tal vez influyó en que un roble fuera incorporado a las monedas de la naciente República. También, entre 1846 y 1848 residió en Costa Rica el naturalista danés Anders S. Oersted, quien recolectó y describió especies nuevas de plantas y animales de Costa Rica y dibujó el primer mapa detallado de la región central del país (Hilje Quirós, 2013).
En relación con esto, la Casa de Moneda sería dirigida a partir de 1860 por otro inmigrante alemán, el Dr. Wilhelm Witting, quien grabó las monedas con sus iniciales G.W. entre 1854 y 1890 (Figura 4). Don Guillermo, nombre con el que fue conocido en el país, también aplicó sus conocimientos científicos al estudio de los suelos agrícolas y a la formulación de abonos. Además, durante la Campaña Nacional (18561857) fue Teniente Coronel, traductor y edecán del presidente Mora y recibió la Cruz de Honor (La Gaceta-Diario Oficial, editorial del 27 de enero de 1896). Cabe destacar que las medallas de la Campaña Nacional son hoy objetos muy buscados por los interesados en la numismática costarricense (ver Murillo, 2004).

\section{Las monedas de la encina 1850-1875}

En la Figura 3 se ha incluido ejemplos de las monedas emitidas con valor de $1 / 4,1 / 8$ y $1 / 16$
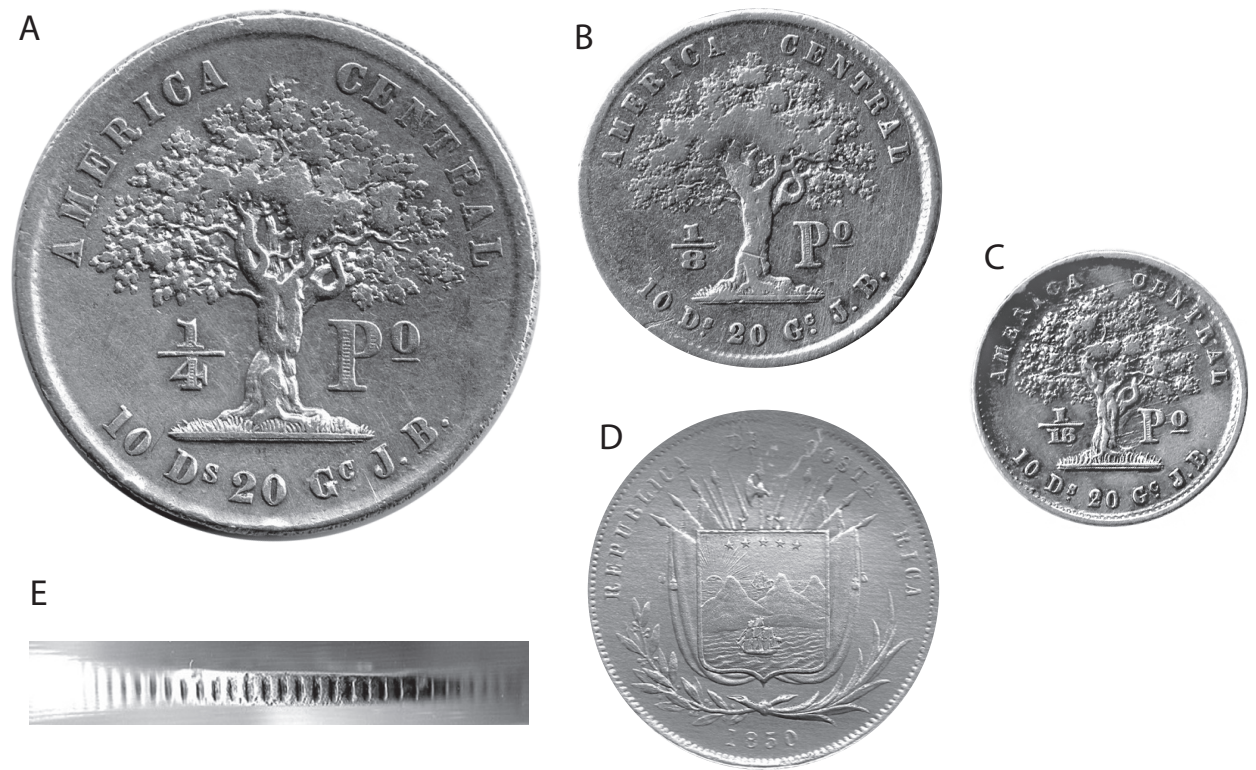

Figura 3

Monedas de Costa Rica con la encina en el reverso (1850-1862): A. Un cuarto (1/4) de Peso, 1850, 24 mm. B. Un octavo (1/8) de Peso, 1850, 19 mm. C. Un dieciseisavo (1/16) de Peso, 1850, 14 mm. 10D 20G = 903/1000 de plata, J. B. (Juan Barth).

D. Prueba, en cartón, del troquel del anverso de la moneda de un Peso, 1850, (38 mm, no acuñada), con el Escudo de Armas. En la base a la izquierda una rama de mirto (Myrtus communis) símbolo de paz. A la derecha una palma de la palmera datilera Phoenix dactylifera, símbolo de victoria y fortaleza. E. Detalle del canto estriado vertical de la moneda de $1 / 4$ de peso (igual tipo en B y C). 
de Peso y fechadas entre 1850 y 1862 . En la Figura 4 se ilustran ejemplos de aquellas emitidas con valor de $50,25,10$ y 5 centavos fechadas entre 1864 y 1875 .

Así pues, en las monedas fue grabada una encina de tamaño mediano, con tronco y ramas gruesas y retorcidas que dan la idea de un árbol centenario y robusto. Según Morales (2010) en Costa Rica algunas encinas alcanzan alturas de más de 40 metros con troncos más o menos rectos. Según lo indica Murillo (2004) algunos de los troqueles para la acuñación de monedas fueron fabricados en la Casa de Moneda en San José, pero otros entre 1850 y 1893 fueron fabricados en Inglaterra y en Alemania, países en los que las encinas como Quercus robur eran y son comunes. Cabe entonces la posibilidad de que el árbol grabado en las monedas esté basado en una especie europea. Cualquiera que fuera el origen del grabado, el árbol escogido como símbolo era conocido tanto en los países con los cuales se esperaba fortalecer los nexos como en Costa Rica, donde árboles solitarios o formando encinares eran abundantes en el siglo XIX, desde las tierras bajas hasta las alturas de las cordilleras. De acuerdo con esto, se puede afirmar entonces que el grabado de una encina en el reverso de las monedas de plata de la joven República de Costa Rica tenía la intención de transmitir un mensaje concreto a los usuarios. Uno de los mensajes de la encina podría haber sido:

\section{“Costa Rica, República en la América Central, robusta y hospitalaria"}

Sobre el mensaje del Escudo de Armas de la República grabado en el anverso de las monedas, véase Vargas Zamora y Sibaja Cordero (2007).

De acuerdo con lo anterior surge la pregunta frecuente entre los interesados en las monedas costarricenses, sobre cuál podría haber sido la especie del árbol grabado en las monedas. Esto en el caso de que los troqueles hubieran sido fabricados por la Casa de Moneda, o que un dibujo de las monedas fuera enviado al extranjero como guía para la elaboración de los troqueles. Si
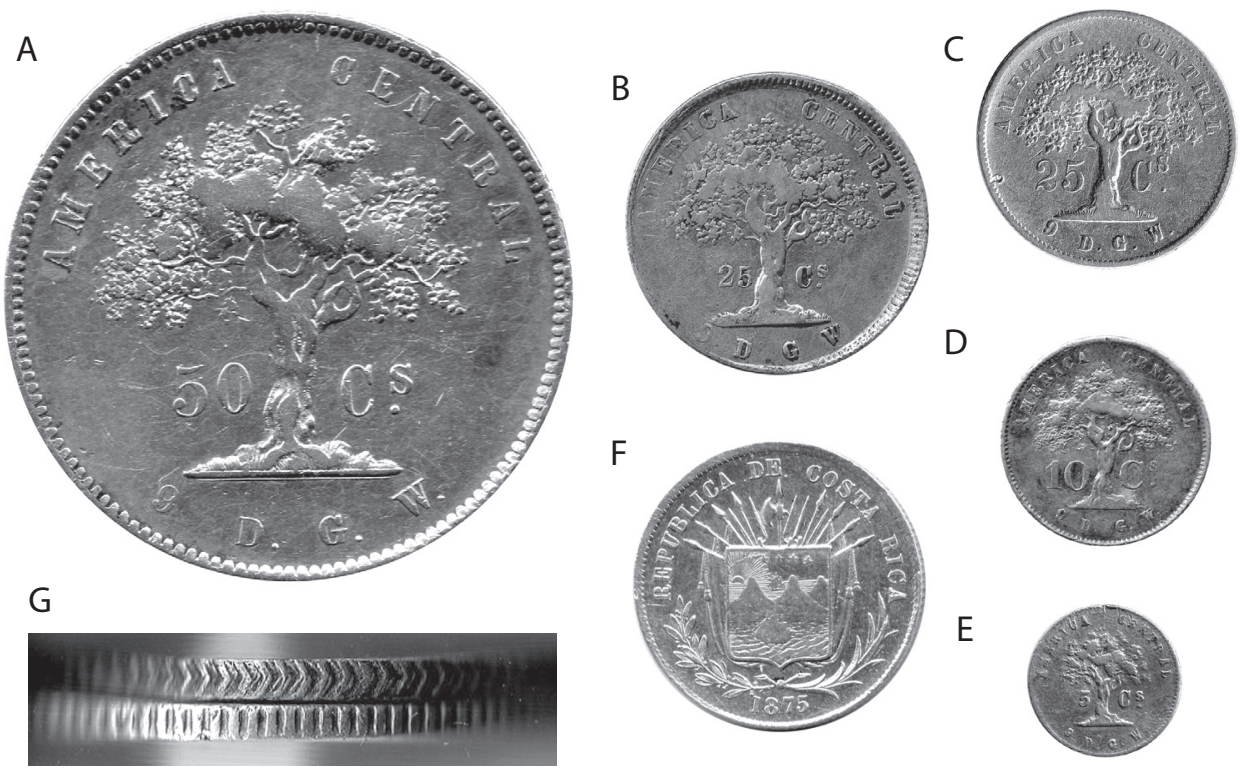

D

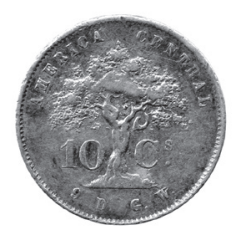

Figura 4

Monedas de Costa Rica con la encina en el reverso (1864-1875): A. Cincuenta centavos (50 C $\left.{ }^{\mathrm{s}}\right), 1875,33 \mathrm{~mm}$. B. Veinticinco centavos (25 C $\mathrm{C}^{\mathrm{s}}$, número pequeño), $24 \mathrm{~mm}$. C. Veinticinco centavos (25 $\mathrm{C}^{\mathrm{s}}$, número grande), 1875, $24 \mathrm{~mm}$. D. Diez centavos $\left(10 \mathrm{C}^{\mathrm{s}}\right), 1865,19 \mathrm{~mm}$. E. Cinco centavos $\left(5 \mathrm{C}^{\mathrm{s}}\right), 1875,15 \mathrm{~mm} .9 \mathrm{D}=750 / 1000$ de plata, G. W. (Guillermo Witting). F. Anverso con el Escudo de Armas y plantas como en la Figura 3. G. Arriba: Detalle del canto estriado en ángulo de la moneda de $25 \mathrm{C}^{\mathrm{s}}$ de 1864, ilustrada en B. Abajo: Detalle del canto vertical de la moneda de 25 Cs (1875). 
ese fue el caso, se supone que el grabador de la Casa se habría inspirado en alguna encina de las cercanías de San José y entonces el roble Quercus salicifolia es un buen candidato pues todavía se encuentran ejemplares con cierta facilidad. En el Campus Rodrigo Facio de la Universidad de Costa Rica existe un ejemplar de Quercus salicifolia que fue sembrado en 1968 y posee algunas similitudes con la encina grabada en las monedas, como el tronco más o menos recto, ramificado a baja altura, y la organización del follaje (Figura 5A, B ,C).

\section{De reales y centavos}

El 11 de diciembre de 1863 se adoptó en Costa Rica el sistema decimal $(1$ Peso $=100$ centavos) y en setiembre de ese año se decide continuar con el grabado del árbol de encina en las monedas (Murillo, 2004).

Sin embargo, cabe mencionar que el vocabulario colonial de los reales sobrevivió en Costa Rica hasta finales del siglo XX, cuando a principio de la década de 1980 la devaluación del colón hizo obsoletas las monedas fraccionarias
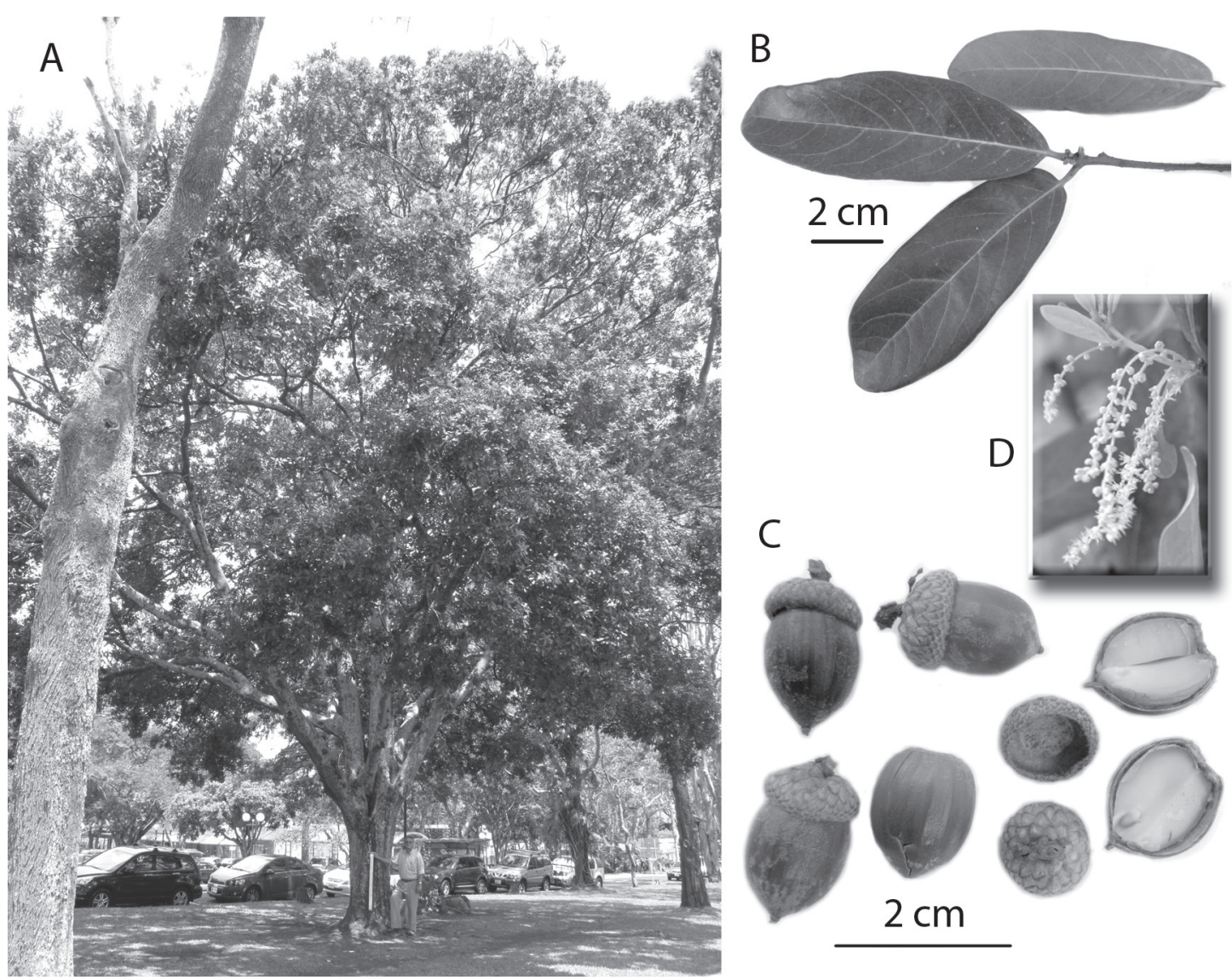

Figura 5

A. Ejemplar de roble-encino (Quercus salicifolia) de $15 \mathrm{~m}$ de altura (la cinta blanca que sostiene el autor mide $1 \mathrm{~m}$ ) y $2 \mathrm{~m}$ de circunferencia (a $1.5 \mathrm{~m}$ sobre el suelo), en crecimiento (Mayo, 2013) en el campus de la UCR (San Pedro de Montes de Oca, frente a la Escuela de Biología) y sembrado en 1968 por el botánico Dr. Luis A. Fournier Origgi. Nótese el tronco más o menos recto, ramificado a $2 \mathrm{~m}$ de altura y follaje en grupos similares a los de la encina en las monedas. B. Hojas oblongas de borde liso y ápice romo que algunos asocian con la escasa $Q$. sapotifalia. C. Frutos (bellotas), copas y nuez interna. D. Flores (Junio 14, 2013). 
del mismo: 25 céntimos $=2$ reales o peseta, 50 céntimos $=4$ reales o cuatro, y 75 céntimos $=6$ reales, además de los cincos y los dieces $(5$ y 10 céntimos). El autor de este escrito pagaba (al inicio de la década de 1970) con dos reales el pase (pasaje) del bus entre el mercado central de San José y la Universidad de Costa Rica en San Pedro y recibía del chofer un cinco vuelto (cinco céntimos de cambio). Así, hablar en términos de reales y céntimos no fue extraño para el costarricense por más de un siglo.

Durante los años en que circularon las monedas con la encina fueron conocidas como las de arbolito, nombre con el cual hoy las identifican los coleccionistas. De este modo, Magón, el escritor costumbrista, menciona el uso de céntimos, cuatros y pesetas en la compra de tragos de licor, tabaco y cuerda en el cuento Taquilla, pulpería y tercena, fechado en 1896, así (González Zeledón, 1968):

(...) - Buenos días, don Serapio, écheme una cususa de a diez, con gotas y gavilana pa' quitarme la goma.

Al mío mel'echa mermú.

Péseme media libra de iztepeque y me mide vara y media de sondaleza.

¿No jue un cuatro el que le dí?

No, señor, fue una peseta.

¿Entonces que haría yo un cuatro de arbolito que traiba?

- Sepa Judas...

En ese mismo cuento se hace referencia a la existencia de monedas de 50 y 25 centavos falsificadas: "Clavados en el borde del despacho del guaro diacuatros y diadoses falsos".

Por otra parte, la falsificación de monedas locales y la circulación de extranjeras con poco contenido de plata y de falsas fueron problemas frecuentes en Costa Rica (Murillo, 2004). Esto hacía necesario que la Casa de Moneda revisara cada una y colocara una marca (rese1lo) en aquellas monedas que cumplían con las normas de calidad. (Ejemplo Figura 2E).

\section{Las monedas emitidas}

En los Cuadros 2 y 3 se menciona las características de las monedas emitidas entre
$1850-1862$ y $1864-1875$, respectivamente. Ambos cuadros contienen estimaciones de los números de monedas acuñadas y que se elaboran con base en los costos de las emisiones tabulados en el Cuadro de las monedas acuñadas en la República publicado en 1883, y reproducido en Murillo (2004). Para los cálculos se asumió una relación 1:1, por ejemplo: 100 pesos $=400$ monedas de $1 / 4$ de Peso. Sin embargo, el número exacto es desconocido y fue afectado por el precio del metal plata a la fecha de cada emisión, según se indica al pie del Cuadro de 1883.

En el Cuadro de 1883 no se indica si en los costos tabulados están incluidos los del resellado de monedas y retroquelado de algunas. Por ejemplo, la de 25 centavos de 1864 ilustrada en la Figura 3 tiene un canto diferente al de las otras y podría ser una pieza retroquelada; es decir, acuñada sobre una moneda preexistente.

\section{La escasez de moneda}

Sumando los totales en los Cuadros 2 y 3 se llega a una cantidad aproximada de monedas con la encina de alrededor de 1.871.171. Esta cantidad podría ser considerada insuficiente para satisfacer las necesidades de una población en las cuatro ciudades principales del Valle Central estimada en 105.000 personas en 1864 y en 157.000 en 1883 (datos en Gudmundson, 1993). En 1864 habría entonces disponibles por persona unas 18 monedas de plata con la encina.

Wilhelm Marr, quien visitó en 1853 la Plaza Principal (hoy Parque Central) de San José un sábado, día de mercado, anotó:

(...) se compra para poder comprar, adquiriendo granos de cacao que hacen las veces de la moneda de cobre; porque la más pequeña de plata, medio real equivale a 1/16 de dólar y varios productos tales como plátanos, naranjas, etc., son tan baratos que por ese precio dan demasiados para que los pueda llevar una persona...(Marr 2004).

De lo anterior se puede inferir que, especialmente antes de las emisiones del sistema decimal y de la introducción de moneda de cobre, la moneda de plata de baja denominación probablemente escaseaba para las operaciones comerciales rutinarias menores, como la compra de alimentos y dar cambio, así como facilitaba 
Cuadro 2

Características y fechas de emisión de las monedas con la encina (1850-1862) y estimación* del número de piezas acuñadas.

Nomenclatura modificada (1850-1862): 16/16 = 1 Peso

Metal: plata. Ley: 903/1000

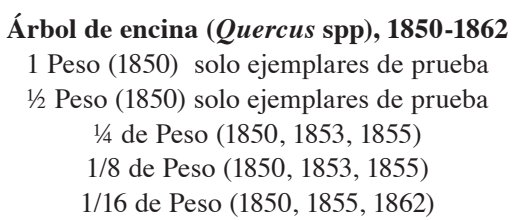

Estimación del número de monedas de 1/4, 1/8, y 1/16 de Peso:

1/4 Peso (Tabulado en el Cuadro bajo Veinticinco cts 1852-56): 9.486,75 + 336,50 + 495,75 + 154,50 = 10.473,50 pesos

(Equivalente** a 41.894 monedas). Posiblemente las monedas con fecha 1850 fueron acuñadas a partir de 1852, pues en 1849 se hizo una emisión importante de piezas de dos reales con el árbol de ceiba y no aparecen costos de emisiones para 1850 y 1851.

1/8 Peso (Tabulado en el Cuadro bajo Un real 1852-56): 9.444,62 + 150,25 + 162,25 + 1211,12 = 10.968,25 pesos (Equivalente** a $\mathbf{8 7 . 7 4 6}$ monedas). Es posible que monedas de 1 real tipo ceiba (1849) y tipo mariquita (1850), fueran acuñadas incluso en 1850 y 1851 respectivamente, por lo que no incluyo los costos tabulados para 1850 y 1851 .

1/16 Peso (Tabulado en el Cuadro bajo Medios reales $1855-62$ ): $131.81+111.87+232.62+427.5=903.8$ pesos (Equivalente** a $\mathbf{1 4 . 4 6 1}$ monedas).

Total aproximado de monedas con la encina (1850-1862): 144.101

* Hechas con base en los datos sobre el costo en Pesos de las emisiones tabuladas en el Cuadro de las monedas acuñadas en la República, desde el año 1829 a 1882, según libros de la Casa de Moneda, hecho por M. Quirós (1883) y reproducido en Murillo (2004:197).

** Equivalente $=$ número de monedas de cada valor y equivalentes al costo de la emisión asumiendo una relación teórica de 1:1.

la introducción de monedas falsas mencionadas antes. Sobre estos temas nos informa Viales Hurtado (2012):

(...) la moneda de baja denominación era relativamente más escasa que la de alta denominación y la política monetaria no subsanó el problema notorio de la falta de moneda para las transacciones consuetudinarias, de allí que el espacio para la falsificación y la circulación de moneda falsa y de baja calidad permaneció abierto durante todo el periodo, y la existencia de este tipo de moneda ocasionó el atesoramiento de la moneda de alto valor y buena calidad (Ley de Gresham)...

\section{La escasez de plata y las piezas de cobre}

En 1845 se había emitido moneda de plata de $1 / 4$ de real o cuartilla (Figura 6A), cuyo costo de emisión fue de 443 pesos según el Cuadro de 1883 mencionado antes. Si un Peso valía 32 cuartillas, ese costo equivaldría aproximadamente a 14.176 monedas. El hecho de que Marr (2004) no observara en circulación esa moneda en 1853 indica que ya no circulaba, no obstante según su relato esa denominación era necesaria y se utilizaban granos de cacao para sustituirla en parte. En Costa Rica los granos de cacao fueron usados como moneda por los indígenas y luego adoptados como medio de pago por los colonizadores. Según Chacón Hidalgo (2008) su uso como moneda fue oficializada partir de 1709. Asimismo, Magón, quien nació en 1864, menciona en su cuento Un día de mercado en la Plaza Principal el uso cuando era niño de granos de cacao para comprar melcochas, mangos, limas y chinchibí y el desuso de los mismos antes de 1896, año en que escribió ese relato (González Zeledón, 1968). 
Cuadro 3

Características y fechas de emisión de las monedas con la encina (1864-1875) y estimación* del número de piezas acuñadas.

Sistema decimal (1864-1896): 100 centavos $=1$ Peso

Metal: plata. Ley $750 / 1000$

Árbol de encina (Quercus spp.), 1864-1875

50 centavos $(1865,1866,1867,1870,1872,1875)$

25 centavos $(1864,1865,1875)$

10 centavos $(1865,1868,1870,1872,1875)$

5 centavos $(1865,1869,1870,1871,1872,1875)$

Estimación del número de monedas de 50, 25, 10 y 5 centavos:

\begin{tabular}{lrrr}
\hline & Valor de la emisión $($ Pesos) & Equivalente** & Monedas*** \\
\hline $50 \mathrm{cvs}$ & $\mathbf{1 1 3 . 1 4 4 , 5 0}$ & $\mathbf{2 2 6 . 2 8 9}$ & $\mathbf{2 2 6 . 4 3 5}$ \\
$25 \mathrm{cvs}$ & $\mathbf{9 6 . 4 6 5 , 7 5}$ & $\mathbf{3 8 5 . 8 6 3}$ & $\mathbf{3 8 6 . 0 0 0}$ \\
$10 \mathrm{cvs}$ & $\mathbf{5 2 . 7 5 2 , 4 0}$ & $\mathbf{5 2 7 . 5 2 4}$ & $\mathbf{5 4 7 . 0 0 0}$ \\
$5 \mathrm{cvs}$ & $\mathbf{2 9 . 3 6 9 , 7 0}$ & $\mathbf{5 8 7 . 3 9 4}$ & $\mathbf{5 8 8 . 0 0 0}$ \\
\hline Totales: & $291.732,35$ & $\mathbf{1 . 7 2 7 . 0 7 0}$ & 1.747 .435 \\
\hline
\end{tabular}

* Hecha con base en los datos sobre el costo de las emisiones tabuladas en el Cuadro de las monedas acuñadas en la República, desde el año 1829 a 1882, según libros de la Casa de Moneda, hecho por M. Quirós (1883) y reproducido en Murillo (2004:197).

** Equivalente (= número de monedas de cada valor y equivalentes al costo de la emisión asumiendo una relación teórica de 1:1).

*** Total de monedas acuñadas según el catálogo de Krause y Mishler (2001: 276-277).

No obstante, fue hasta 1865 que se acuñó por primera vez las monedas de cobre-níquel de un centavo (también emitidas con fecha 1866, 1867,1868 y 1874) y de $1 / 4$ de centavo (1865), Figura 6B. Con esto, medio real equivaldría a unos 6 centavos. La de 1/4 de centavo probablemente estaba en el límite inferior de utilidad y rápidamente se tornó obsoleta (Murillo, 2004). Es posible además que por su pequeño tamaño las de $1 / 4$ de real (diámetro $11 \mathrm{~mm}$ ) y las de $1 / 4$ de centavo $(12.5 \mathrm{~mm})$ fueran incómodas de manejar para la gente de la época. Las monedas más pequeñas con la encina ( $1 / 16$ de Peso y 5 centavos) tienen diámetros de 14 y $15 \mathrm{~mm}$, respectivamente y 20 $\mathrm{mm}$ las de un centavo.

Por un lado, la escasez de moneda de baja denominación durante gran parte del siglo XIX ha sido propuesta por Chacón Hidalgo y Carazo de Flores (2006) como una de las razones por las cuales se utilizó moneda sustituta, como los boletos para pagar a los recolectores de café en los cafetales y a las escogedoras en los beneficios. En la Figura 6C se ha incluido un boleto del cafetalero Narciso Esquivel (N.E.) quien inició operaciones hacia 1841 en la zona de La Uruca. El boleto de bronce, por valor de 25 cs (centavos), tiene grabadas dos ramas fácilmente asociables por la forma de las hojas a la encina europea Quercus robur.

La escasez de moneda probablemente se acentuaba ocasionalmente. En este sentido cabe mencionar que la operación de la Casa de Moneda de Costa Rica no fue continua desde su fundación en 1828 , pues hubo varios períodos en los que permaneció cerrada por diversos motivos y fue reabierta algunas veces cuando había necesidad de circulante, tal como se indica en un informe del gobierno en 1861:

(...) Casa de Moneda. Continúa cerrado éste establecimiento; pero se mantienen los dos empleados necesarios para que las máquinas y demás enseres que le pertenecen, no sufran detrimento alguno. Dos veces ha sido abierto en el último año para la amonedación de varias cantidades de oro en pastas, que no eran de fácil circulación, y que hacía falta para las transacciones. La intención del Gobierno es de conservarla de la misma manera, abriéndolo temporalmente cada vez 
A
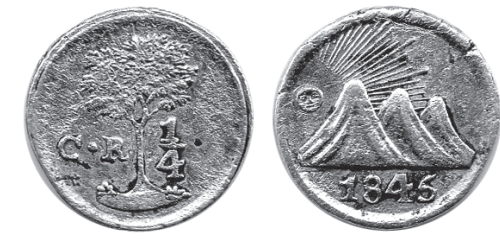

B
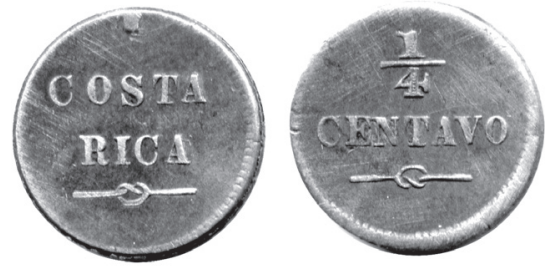

C
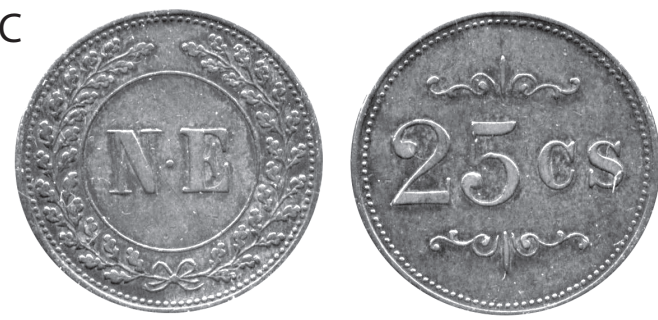

D
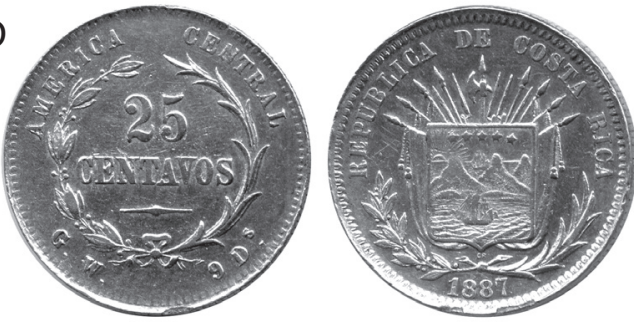

$\mathrm{E}$
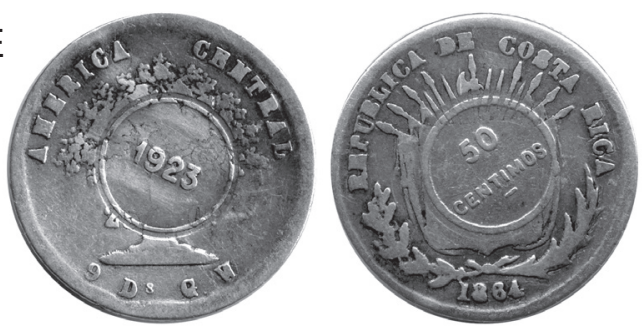

Figura 6

A. Un cuarto (1/4) de real o cuartilla, 1845, $11 \mathrm{~mm}$. La moneda de plata de menor diámetro y valor emitida en Costa Rica (C.R.). Arbol de ceiba. B. Un cuarto (1/4) de centavo, 1865, $12.5 \mathrm{~mm}$. La moneda de cupro-níquel de menor valor emitida en Costa Rica. C. Boleto de café, bronce, $25 \mathrm{~mm}$, N.E. (Narciso Esquivel, La Uruca). Bronce. Ramas de Quercus robur. D. Veinticinco centavos o peseta, 1887. $25 \mathrm{~mm}$. Corona de mirto (Myrtus communis) a la izquierda y una palma (Phoenix dactylifera) a la derecha. E. Veinticinco centavos, 1864, encina resellada en 1923 para circular por valor de 50 céntimos. que la necesidad y la conveniencia pública lo demanden (Montealegre, 1861).

El Cuadro de 1883 también nos proporciona pistas sobre el por qué algunas monedas con la encina son muy difíciles de obtener actualmente por parte de los coleccionistas. A continuación tres ejemplos: 1) Los cuartos de Peso de 1853 y 1855. Las emisiones correspondiente en el Cuadro tuvieron costos de 336.50 y 650.25 pesos, para estimados de 1.346 y 2.601 monedas, respectivamente. 2) Un dieciseisavo de Peso 1862 (costo de emisión: 425.50 pesos), para un estimado de 6.808 monedas. 3) Cincuenta centavos de 1870 y 1872 (costo de emisión: 3.133,5 pesos), para un estimado de 6.277 monedas.

Sin embargo, para las emisiones de 1870 , 1871 y 1872 (Cuadro 3) se debe tomar en cuenta otro factor, que se menciona a continuación.

\section{El ocaso de las monedas con la encina}

Desde tiempos coloniales hasta por ahí de 1870 el sistema monetario utilizado en Costa Rica era bimetálico; es decir, circulaban monedas de oro y de plata intercambiables entre sí. La relación entre ambos metales fluctuaba levemente alrededor de 16:1 (16 monedas de un real de plata equivalían a una moneda de oro de un escudo). Según Young (1925) alrededor de 1870 el valor de la plata comenzó a caer en el mercado internacional y la relación 16:1 no se podía mantener. $\mathrm{La}$ moneda de plata pasó entonces a ser una moneda mala (se devaluó con respecto a la de oro) que desplazaba a la buena (la de oro), la cual era atesorada o exportada. Esto se conoce como la Ley de Gresham, mencionada antes.

En 1871 don Tomás Guardia decretó la Ley de la Moneda que, entre otras cosas, descontinuaba el uso de un árbol de encina grabado en las monedas, pues estaba construyéndose otro modelo de gobierno asociado a nuevos símbolos. Como parte de esos cambios se había ordenado fabricar en el extranjero troqueles que incluían el nuevo diseño (que se utilizaría a partir de 1880), pero que tenían grabado un contenido de plata de 835/1000. De acuerdo con Murillo (2004) la caída del precio de la plata forzó entonces al gobierno a continuar utilizando los troqueles con el árbol 
de encina y acuñar monedas con menor contenido de ese metal

No obstante el ingreso a partir de $1880 \mathrm{del}$ nuevo tipo de monedas con la corona de mirto y palma (Figura 6D), las antiguas con la encina continuaron circulando por varios años, como lo indica el primero de los cuentos de Magón citados. Si las monedas acuñadas con fecha 1875 hubieran circulado por solo cinco años deberían entonces existir hoy muchos ejemplares con poco desgaste. Sin embargo, en la actualidad es difícil encontrar monedas en buen estado de conservación, especialmente las de mayor diámetro, como los cuatros (50 centavos, $33 \mathrm{~mm}$ ). Además, antes de que la numismática fuera un pasatiempo popular en Costa Rica, muchas monedas de plata y oro en diferentes estados de conservación fueron fundidas para utilizar los metales preciosos en joyería.

Por otra parte, con fecha 1923 se resellaron monedas de plata por el doble de su valor; es decir, las de 25 y 50 centavos anteriores a 1894 y las de 50 céntimos (1902 a 1918) pasaron a valer 50 céntimos y un colón, respectivamente (Chacón Hidalgo, 2007). Como parte de las monedas reselladas se incluyeron algunas con la encina grabada, como la peseta de 1864 ilustrada en la Figura 6E, lo que indica que todavía eran aceptadas, pues por contener un metal precioso (plata) tenían valor por sí mismas. Las últimas monedas con algún contenido de plata (650/1000) que circularon en Costa Rica fueron las pesetas fechadas 1924.

\section{El contenido de plata $y$ el peso de las monedas}

En las monedas ilustradas en la Figura 3 se indica el contenido de plata como $10 \mathrm{D}^{\mathrm{s}} 20 \mathrm{G}^{\mathrm{s}}$ y las letras J. B. (Juan Barth) del ensayador que lo certificó. Del mismo modo, las incluidas en la Figura 4 indican el fino con 9D y el ensayador con las letras G. W. (Guillermo Witting).

Para la plata se asume que el metal puro equivale a 12 Dineros o 1000/1000 (Blanchet y Dieudonne (1916). Por regla de tres, 10D equivalen a 833.33/1000. Un Grano equivale a 1/24 del Dinero, o sea 3.47. Por lo tanto, 10D $+20 \mathrm{G}$ corresponden a una moneda con 902.77 milésimas (redondeadas a 903/1000) de plata pura. Una moneda con 9D contiene entonces $750 / 1000$ de plata y el resto (250/1000) generalmente era cobre para darle dureza.

Sobre el peso de las monedas debemos recordar que desde 1728 la moneda colonial de ocho reales o Peso fuerte debía pesar 27.064 gramos y cada denominación inferior pesaba en teoría la mitad de la superior inmediata; esto es: $13.532 \mathrm{~g}$ (4 reales), $6.766 \mathrm{~g}$ ( 2 reales), 3.383 g (1 real), $1.691 \mathrm{~g}(1 / 2$ real) y 0.845 (1/4 real). Sin embargo, desde esa época, el peso de las monedas fue objeto de oscilaciones generalmente hacia la baja. Por ejemplo, según Murillo (2004) en el decreto emitido el 20 de julio de 1849 se establecen los pesos en granos (1 grano equivale aproximadamente a 0.05 gramos) así: 1 Peso $=$ 480 granos (24.0 gramos), $1 / 2$ Peso $=240(12.0 \mathrm{~g})$, $1 / 4$ de Peso $=120(6.0 \mathrm{~g})$, el real $=60(3.5 \mathrm{~g})$ y el medio real $=30(1.5 \mathrm{~g})$.

En el Cuadro 4 se ha incluido los pesos en gramos de las monedas con muy poco desgaste ilustradas en las Figuras 3 y 4, así como los citados en el catálogo de Krause y Mishler (2001). Solo dos de las monedas mostraron pesos superiores al teórico y una el peso esperado. Las diferencias más notables corresponden a las monedas de menor tamaño, como el $16^{\text {avo }}$ de Peso (superior) y la de 5 centavos (inferior). Un estudio con una muestra mayor de piezas en buena condición permitiría evaluar esas diferencias mediante análisis estadístico.

\section{La encina sobrevivió en billetes}

El Banco Anglo Costarricense (1863-1994) hizo imprimir en Inglaterra 10.000 billetes de cinco pesos fechados 1 de enero de 1864 y que fueron utilizados entre 1864 y 1877. En estos destaca a la izquierda la efigie de la princesa de Gales (Alexandra de Dinamarca) y en el centro el dibujo de un árbol semejante a la encina grabada en monedas. Recordemos que la encina es un árbol de importancia simbólica en Inglaterra. De estos billetes según Carranza Astúa (2012) no se conservan ejemplares firmados. Posiblemente para representar a la contraparte de accionistas costarricenses del Banco, en el billete de un Peso 
Cuadro 4

Peso en gramos de las monedas con la encina: A. Según el catálogo de Krause y Mishler (2001: 276-277).

B. Peso de los ejemplares con poco desgaste ilustrados en las Figuras 3 y 4 . A-B. Diferencia entre los pesos en gramos.

C. Porcentaje de diferencia entre los pesos.

\begin{tabular}{lcccc}
\hline & A & B & A-B & C \\
\hline Ilustradas en la Figura 3: & & & & \\
$1 / 4 \mathrm{P}^{\circ} 1850$ & 6.40 & 6.19 & -0.21 & -3.3 \\
$1 / 8 \mathrm{P}^{\circ} 1850$ & 2.95 & 2.95 & 0.00 & 0.0 \\
$1 / 16 \mathrm{P}^{\mathrm{o}} 1850$ & 1.46 & 1.58 & +0.12 & $\mathbf{+ 8 . 2}$ \\
\hline Ilustradas en la Figura 4: & & & & \\
$25 \mathrm{C}^{\mathrm{s}} 1864$ & 6.25 & 6.48 & +0.23 & +3.7 \\
$10 \mathrm{C}^{\mathrm{s}} 1865$ & 2.53 & 2.35 & -0.18 & -7.1 \\
$50 \mathrm{C}^{\mathrm{s}} 1875$ & 12.50 & 12.41 & -0.09 & -0.7 \\
$25 \mathrm{C}^{\mathrm{s}} 1875$ & 6.25 & 6.18 & -0.07 & -1.1 \\
$5 \mathrm{C}^{\mathrm{s}} 1875$ & 1.26 & 1.10 & -0.16 & $\mathbf{- 1 2 . 7}$ \\
\hline
\end{tabular}

se grabó un volcán humeante. De estos billetes se conservan cinco ejemplares firmados.

Sin embargo, la sustitución a partir de 1880 del árbol de encina por una corona formada por dos ramas, una de la palma datilera (Phoenix dactylifiera) y la otra del mirto (Myrtus communis, símbolo de paz) en el anverso de las monedas (Figura 6D), no significó la desaparición de la encina y de su simbolismo, pues sobrevivieron en otro medio de pago, los billetes bancarios de la primera mitad del siglo XX.

Entre 1906 y 1943 el árbol de encina fue sustituido por una parte del mismo (una rama) grabada en billetes. Por ejemplo, en la Figura 7A,B se ilustra parte del anverso del billete de dos colones emitido en 1919 por el Banco Internacional de Costa Rica (B.I.C.R.), cuyo grabado e impresión fue hecho por American Bank Note Co. (Nueva York, E.U.A). De acuerdo con Chacón Hidalgo y Alvarado Venegas (2001) en esos billetes (un total de 875.000 fechados entre 1918 y 1931) la diosa Atenea (con casco guerrero), aparece mirando al frente, con libros al pie, una antorcha y un león dormido. Ella sostiene una rama de encina (por la forma de las hojas parece Quercus robur), tal vez para indicar la fortaleza de la entidad bancaria, de la República, o de ambas. Sobre esta ilustración en particular nos dicen:
(...) Sin duda ésta es la representación simbólica de la República, en el sentido amplio de un cuerpo de instituciones que vigilan para preservar las libertades, los derechos y las instituciones construidas con esfuerzo. La razón se mantiene despierta mientras la fiereza duerme (Chacón Hidalgo y Alvarado Venegas, 2001).

En el reverso de esos billetes (Figura 7C,D) aparece el busto de una mujer con gorro frigio que representa a la libertad (Harden, 1995). La figura lleva una corona hecha con una rama de encina, que por la forma de las hojas y de las bellotas nuevamente se puede asociar a la encina europea Quercus robur.

Según Carranza-Astúa (2012), con anterioridad a 1919, el Banco Comercial de Costa Rica (1905-1915) había incluido ese mismo símbolo en sus billetes de 5, 10, 20, 50 y 100 colones emitidos entre 1906 y 1914 (cerca de 260.000 billetes). La libertad coronada también fue grabada por el Banco Internacional de Costa Rica (1914-1936) en 1.400 .000 billetes de 1 colón (1918-1935) y 255.850 de 20 colones (1916 y 1919-1936). Su sucesor, el Banco Nacional de Costa Rica reselló y puso a circular 100.000 billetes del B.I.C.R. de 20 colones (1937-1938) y 200.000 de 1 colón (1943) en los que destaca esa representación de la libertad coronada. Arriba y en la base del óvalo que contiene la efigie de la libertad (Figura 7D) 

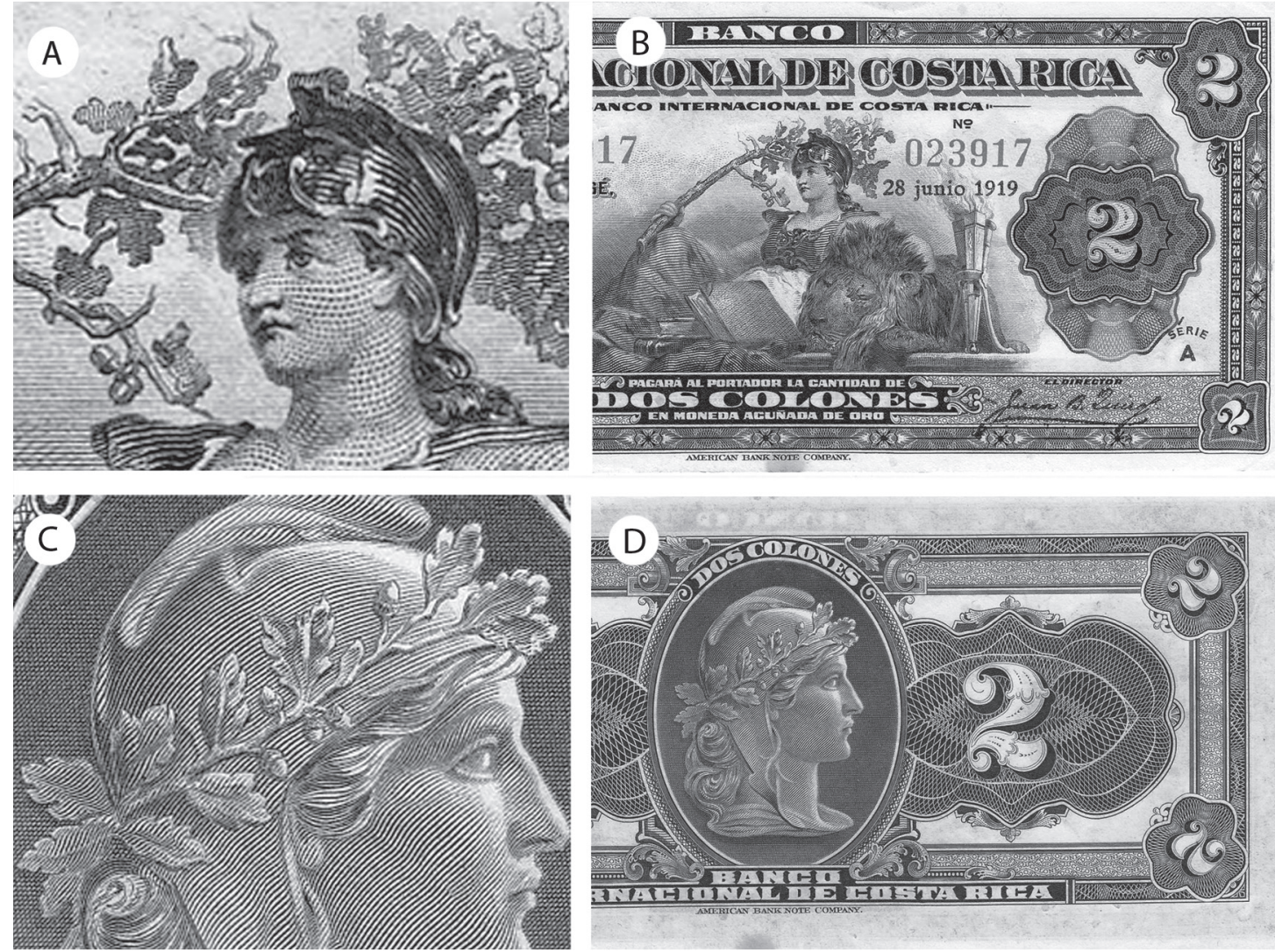

Figura 7

A. Detalle de la rama que sostiene la diosa Atenea con hojas y bellotas de la encina europea Quercus robur. B. Sector derecho del anverso del billete ( 73 x 163 mm, emitidos entre 1918 y 1931) del Banco Internacional de Costa Rica, Serie A, dos colones, del 28 de junio de 1919, mostrando a la diosa reclinada, con libros al pie, una antorcha encendida y un león dormido. C.

Detalle de la corona con la rama de $Q$. robur. D. Sector derecho del reverso del mismo billete de 1919 con la efigie de la Libertad (con gorro frigio).

están dibujados adornos que representan hojas del acanto europeo (Acanthus mollis). Esta decoración botánica (utilizada desde la Grecia antigua en el capitel corintio y en ornamentaciones como las que adornan el Teatro Nacional) no se la asocia con un simbolismo específico. El acanto fue utilizado profusamente en los billetes de Costa Rica desde fines del siglo XIX hasta el 2005 (billete de 500 colones, serie C).

La puesta en circulación de 1.500 .000 monedas de un colón fechadas 1948, sumadas a las 350.000 de 1935 y 300.000 de 1937 (Krause y Mishler, 2004), así como la entrada de los nuevos billetes del Banco Central de Costa Rica a partir de 1950, hizo obsoletos los billetes antiguos y la encina desapareció. Aún así, los símbolos botánicos sobreviven en las monedas de Costa Rica, pues desde 1935 y hasta hoy se graba dos bandolas (ramas) de café en el reverso, aunque las últimas dibujadas con alguna fidelidad biológica son las de 1995. En el anverso se graba el Escudo Nacional, que contiene dos ramas de mirto.

Otra evidencia de la importancia del uso de plantas para transmitir mensajes concretos está grabada en la puerta (Figura 8) del edificio antiguo al costado norte del Colegio de Señoritas, en San José. En esa decoración restaurada destacan dos especies europeas: a la izquierda una rama del laurel (Laurus nobilis) emblema del mérito y utilizada entre 1951 y 1962 en el billete de 10 colones para reafirmar que Aquileo Echeverría es un poeta laureado. A la derecha una 


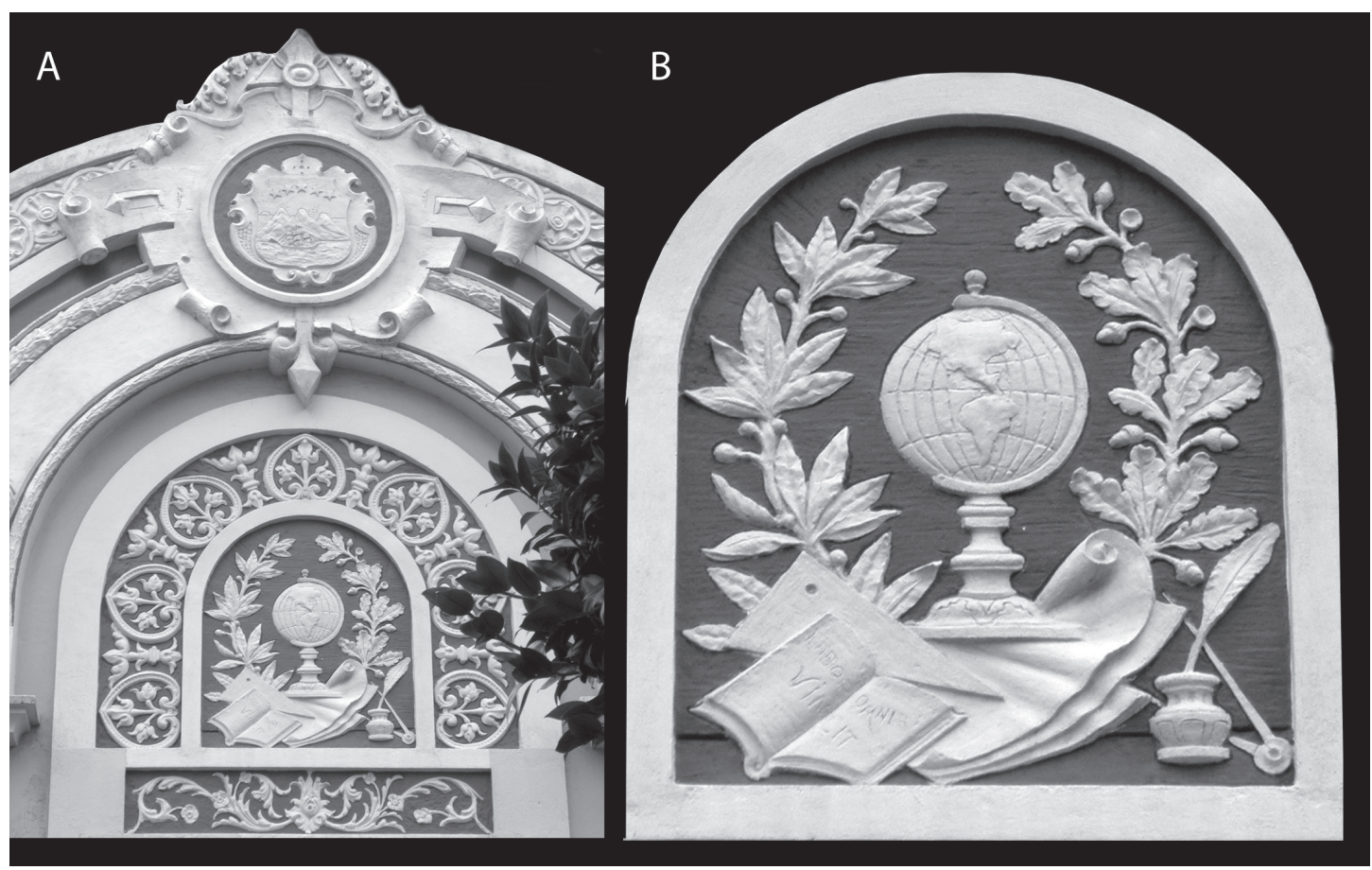

Figura 8

A. Sección superior de la puerta del edificio al costado norte del Colegio de Señoritas, San José. Nótese escudo de armas de 1906. B. Detalle del centro mostrando dos especies de plantas europeas: a la izquierda Laurus nobilis con frutillos y a la derecha Quercus robur con bellotas. Nótese que el mapa de América del Sur está invertido.

rama de Quercus robur, cuyo simbolismo hemos analizado en este escrito.

\section{Conclusión}

Desde su invención hace más de 2.500 años las monedas han transmitido a los usuarios mensajes simbolizados por plantas, animales, $\mathrm{u}$ objetos; es decir, las monedas son además medios de comunicación y de propaganda. En Costa Rica el grabado de plantas en monedas desde 1825 daba a conocer mensajes concretos a nacionales y extranjeros. La encina fue símbolo de fortaleza y de hospitalidad por casi un siglo, primero en monedas y luego en billetes. Del mismo modo, por su abundancia y majestuosidad los grandes árboles de roble, que cubrían gran parte de las tierras altas de Costa Rica a mediados del siglo XIX, eran íconos reconocibles para el costarricense y para el extranjero. Las monedas de arbolito de Costa Rica, acuñadas entre 1850 y 1875, destacan como las primeras del siglo XIX en el mundo en las que se grabó un árbol de roble o encina, en notable contraste con la mayoría de las monedas de ese periodo que tienen grabada la efigie del gobernante de turno. Por ese motivo y por su relativa escasez, son objetos de colección muy apreciados por los interesados en numismática alrededor del mundo. Finalmente, se espera que este escrito contribuya a fomentar su estudio y la conservación de esta herencia numismática. 


\section{Agradecimientos}

A Harlan K. Dean (MCZ, Harvard University, E.E.U.U) por facilitar literatura en idioma inglés y el acceso a la moneda conmemorativa de 1935. A Minor Martín García (Numismática y Filatelia La Granada, San José) por la obtención de varias monedas y el libro de Blasco-Jorro. A Carlos Morales (Escuela de Biología, UCR) por la información sobre el roble-encino de la UCR. A don Franklin Zamora por la referencia de Alfaro y colegas. A Sergio Aguilar por la preparación de las figuras.

Este trabajo esta dedicado a la memoria del amigo, colega e insigne botánico, Prof. Jorge Gómez Laurito (1947-2014).

\section{Referencias bibliográficas}

Alfaro, A., C. H. Lankester, R. A. Chavarría, F. O. Jiménez y J. León. (1944). Informe sobre los robledales de Copey. Resumen del estudio publicado por el Prof. Wm. R. Barbour en Tropical Woods. Revista del Instituto de Defensa del Café de Costa Rica. XIV (114): 293-296.

Bean, W. J. (1919). Abraham's oak. Bull. Misc. Inf. Royal Gardens Kew. 1919(5): 233-236.

Blanchet, A. y A. Dieudonné. (1916). Manuel de numismatique francaise. Tome Deuxieme. Auguste Picard. Paris. Francia. 477 p

Blasco Jorro, M. A. (1815). Compendio de materia médica para el uso de los médicos jóvenes. José Ferrer de Orga, Valencia. España. 278 p.

Boucher, D.H. (1981). Seed predation by mammals and forest dominance by Quercus oleoides, a tropical lowland oak. Oecologia 49 (3): 409 - 414.

Carranza Astúa, J. A. (2012). Historia de los billetes de Costa Rica 1858-2012. J. Carranza A. San José. 498 p.

Carson, R. A. G. (1962). Coins of the World. Harper and Brothers Publishers. New York, N.Y. 770 p.
Cendrero Curiel, O. (1932). Botánica. $6^{\text {ta }}$ ed. Talleres Tipográficos A. Andrey. Santander. España. 294 p.

Céspedes Porras, R. (1991). Fenología de Quercus seemannii Lieb. (Fagaceae), en Cartago, Costa Rica. Revista de Biología Tropical. 39 (2): 243 - 248.

Chacón Hidalgo, M. B. (2000). Del Estado a la República. Las monedas y la política de Costa Rica (1821-1850). 50 Aniversario del Banco Central de Costa Rica. Imprenta y Litografía LIL. San José. 82 p.

Chacón Hidalgo, M. B. y I. Alvarado-Venegas. (2001). Gráfica en el papel moneda (18581936). Fundación Museos del Banco Central. San José. 68 p.

Chacón Hidalgo, M. B. y E. Carazo de Flores. (2006). Boletos de café de Costa Rica. Fundación Museos del Banco Central de Costa Rica. San José. 410 p.

Chacón Hidalgo, M. B. (2007). Resellos de Costa Rica - Costa Rican counterstamps. Fundación Museos del Banco Central de Costa Rica. San José. 20 p.

Chacón Hidalgo, M. B. (2008). El cacao como moneda oficial en la Costa Rica del siglo XVIII. NVMISMA 252: 137-147.

Ciesla, W. M. (2002). Non-wood forest products 15. Non-wood forest products from temperate broad-leaved trees. Food and Agriculture Organization of the United Nations (FAO). Roma. 125 p.

Fernández Guardia, R. (2002). Costa Rica en el siglo XIX. Antología de viajeros. Editorial Universidad Estatal a Distancia. San José. $495 \mathrm{p}$.

González Zeledón, M. (1968). Cuentos. Estudio preliminar, edición y glosario de José Ma. Arce. Antonio Lehmann. Librería, Imprenta y Litografía Ltda. San José. 406 p.

Gudmundson, L. (1993). Costa Rica antes del café: sociedad y economía en vísperas del boom exportador. Editorial Costa Rica. San José. 256 p. 
Gurdián Montealegre, R. (1997). Contribución al estudio de las monedas de Costa Rica. $2^{\text {da }}$ ed. Litografía e Imprenta LIL. San José. $200 \mathrm{p}$.

Harden, J. D. (1995). Liberty caps and liberty trees. Past and Present 146: 66 - 102.

Herrera Balharry, E. (1988). Los alemanes y el estado cafetalero. Editorial UNED. San José. 230 p.

Hilje Quirós, L. (2013). Trópico agreste: la huella de los naturalistas alemanes en la Costa Rica del siglo XIX. Editorial Tecnológica de Costa Rica. Cartago. 865 p.

Klawans, Z. H. (1959). An outline of ancient greek coins. Whitman Publishing Co. Racine. WI. 208 p.

Krause, C. L. y C. Mishler. (2001). Standard catalog of World coins 1801-1900. Krause Publications Inc. Iola. WI. 1.200 p.

Krause, C. L. y C. Mishler. (2004). Standard catalog of World coins. 32 ava ed. 1901-Present. Krause Publications Inc. Iola. WI $2.288 \mathrm{p}$.

Marr, W. (2004). Viaje a Centroamérica. Traducción de Reise nach Central-Amerika (1863) por Irene Reinhold. Editorial de la Universidad de Costa Rica. San José. $472 \mathrm{p}$.

Montealegre, F. (1861). Informe del Secretario de Estado en los Departamentos de Hacienda, Guerra, Marina y Caminos, al Congreso de 1861. Imprenta Nacional. San José. $40 \mathrm{p}+11$ cuadros.

Morales, J. F. (2010). Fagaceae. Quercus. Encino, Roble. p. 776-781. En: B. E. Hammel, M.
H. Grayun, C. Herrera y N. Zamora (Eds.). Manual de Plantas de Costa Rica. Vol. V. Dicotiledóneas. Monographs in Systematic Botany of the Missouri Botanical Garden. Vol. 119.

Murillo, J. (2004). Historia de las monedas de Costa Rica. Catálogo numismático. Editorial UNED, San José. 252 p.

Vargas Zamora, J. A. y J. Gómez Laurito. (2004). Botánica y Numismática: las plantas en las monedas de Costa Rica. Lankesteriana 4 (2): 155 - 168.

Vargas Zamora, J. A. y J. A. Sibaja Cordero. (2007). Reflexiones sobre el Escudo Nacional grabado en monedas de Costa Rica (1850 - 2005). Rev. Reflexiones 86 (2): 141-156.

Vargas Zamora, J. A. y J. Murillo Rivera. (2013). El escudo del Estado de Costa Rica (1840) en el billete de 1.000 colones (2009). Rev. Reflexiones 92 (1): 9 - 22.

Viales Hurtado, R. (2012). La historia monetaria de Costa Rica en el período posterior a la independencia. Del caos monetario a los orígenes del patrón oro (1821-1896). p. 101-219. En: R. Viales-Hurtado (Ed.). Nueva historia monetaria de Costa Rica. De la colonia a la década de 1930. Colección Historia de Costa Rica. Editorial de la Universidad de Costa Rica, San José.

Yeoman, R. S. (1976). A guide book of United States coins. $29^{\text {th }}$ edition. Western Publishing Co. Racine. WI. 256 p.

Young, J. P. (1925). Central American currency and finance. Princeton University Press. Princeton. N. J. 258 p. 
